\title{
Morphometric Study on Some Body Organs of the Wild African Senegal Parrot (Poicephalus senegalus versteri)
}

\section{N. Wanmi ${ }^{* 1}$, A. Mohammed ${ }^{2}$ and T. Nev ${ }^{1}$}

Department Of Veterinary Anatomy, College of Veterinary Medicine, University of Agriculture, Makurdi, Benue State, Nigeria.

Department Of Veterinary Pathology, Faculty Of Veterinary Medicine, University Of Ilorin, Kwara State, Nigeria

\section{With 2 tables \& 2 figures $\quad$ Received August, accepted for publication August 2015}

\section{Abstract}

Parrot population in Africa is declining and the need for conservation actions to address threats is increasingly recognized. The situation is worst in $\mathrm{Ni}$ geria and if care is not taken, this species of bird will soon go into instinct. The essence of this study was to obtain a database of some body organs of the wild Senegal parrot, a species of bird that is limited in its distribution in this part of the country. Documentation on this species of bird is rare despite they are being hunted for because of its demand as ornamental bird. The mean weights (whole body, gastrointestinal tract (GIT), content and GIT empty) were observed to be $120.50 \pm 5.42 \mathrm{~g}, 18.01 \pm 4.80 \mathrm{~g}$ and $13.54 \pm 5.51$ respectively. The liver had mean weight of $4.18 \pm 1.82$ while the tongue, lower respiratory system (LRS), heart and kidney were observed to be, $2.76 \pm 2.14 \mathrm{~g}, 5.83 \pm$ $1.65,1.81 \pm 0.65$ and $0.41 \pm 0.05 \mathrm{~g}$.

J. Vet. Anat.
The mean length (whole body + tail) were observed to be $9.85 \pm 1.20 \mathrm{~cm}$. The mean lengths (GIT, liver tongue and LRS) were $82.62 \pm 2.36 \mathrm{~cm}, 4.33$ $\pm 1.82 \mathrm{~cm}, 2.04 \pm 0.99 \mathrm{~cm}$ and 12.69 $\pm 2.10 \mathrm{~cm}$ respectively with GIT and LRS accounting for $76.93 \%$ and $19.97 \%$ of the body weight. The syrinx is very large suggesting pronounced sound production and the large intestine is void of cecum.

Keywords: body, organ system, wild, Senegal, parrot.

\section{Introduction}

Parrots are gregarious and vocal creatures that communicate in ways we have to understand. It can be quite fun trying to figure out why they do some of the things they do. Body language can reveal whether a pet bird is calm, fearful, aggressive, having fun, wanting attention or if it is displaying mating behavior, Athan and Deter (2000). In the wild, Sene- 
gal Parrots are shy and avoid being approached. This behaviour has a tendency to remain, even in captivity, unless they are handled and socialized at an early age. Throughout their lives, they need human interaction, gentle handling, and stimulation to remain tame and gentle.

Most parrots are quite entertaining in some of their more comical behaviours, such as rolling up in a cloth, lying on their back, or hanging and swinging upside down for extended periods. Although not great talkers (comparatively), they can and will learn to mimic and have a relatively quiet voice. Their antics, size, and more reticent nature make the Senegal a good Parrot population in Africa is declining and the need for conservation actions to address threats is increasingly recognized. The situation is worst in Nigeria and if care is not taken, this species of bird will soon go into instinct, Wright (2002).

Effective conservation need a well knowledge base on which decisions over appropriate actions can be made, yet at present there is rare up to date and readily accessible status of populations, the threats they face and knowledge in this species of bird IUCN (2000).

The essence of this study was to obtain a baseline data of some body organs of the wild Senegal parrot, which are scarcely found and documented. It is known that parrots are being hunted for because of its demand as ornamental bird kept in few private

J. Vet. Anat. schools, institutes, zoos and some individual residential areas.

\section{Materials and Methods}

Three of these birds were caught around Shika village a small farmstead in Northern part of Kaduna State, Nigeria. This species of bird is rare in this part of the country, as such the reason for using the few number stated above. Birds were transported in a standard laboratory cage to the animal unit of the Department of Veterinary Anatomy, Faculty of Veterinary Medicine, Ahmadu Bello University, Zaria. Grains, fried cake and water were given ad libitum for two and half weeks.

Birds were sacrificed, placed on dorsal recumbency and an incision was made from the level of the mandible, through the thorax to the anal region. The cervical, thoracic and abdominal portions of the esophagus were exposed. Weight of the bird was taken using Mettler balance of sensitivity of $0.001 \mathrm{~g}$. Scissor for cutting through thoraco-abdominal region, digital vernier caliper was used for measuring length of organs, digital camera, Sony, 12 mega Pixel, [AS1] was used for macrograph. Measurements were recorded in grams (weight) and centimeters (length).

\section{Statistical Analysis}

Mean \pm Standard Error of Mean (Mean \pm SEM) using Statistical Package for Social Science Version Vol. 8, No. 2, (2015) 81 - 88 
(SPSS) 17 was used in estimating values for weights and length. $P$ < 0.05 was considered significant.

\section{Results}

\section{Morphometric Features}

The mean weights (whole body, GIT + content and GIT empty) were observed to be $120.50 \pm 5.42 \mathrm{~g}, 18.01 \pm$ $4.80 \mathrm{~g}$ and $13.54 \pm 5.51$ respectively. The GIT and its content accounted for $14.94 \%$ of the total body weight. The liver had mean weight of $4.18 \pm 1.82$ while the tongue, LRS, heart and kidney were observed to be, $2.76 \pm 2.14$ g, $5.83 \pm 1.65,1.81 \pm 0.65$ and $0.41 \pm$ $0.05 \mathrm{~g}$. The kidneys had the lowest percentage of body weight of $0.34 \%$ against $1.50 \%$ and $2.29 \%$ for heart and LRS (Table 1)

The mean length of the whole body and tail of the bird was $9.85 \pm 1.20$ $\mathrm{cm}$. The mean lengths of the GIT, liver, tongue and LRS were $82.62 \pm$ $2.36 \mathrm{~cm}, 4.33 \pm 1.82 \mathrm{~cm}, 2.04 \pm 0.99$ $\mathrm{cm}$ and $12.69 \pm 2.10 \mathrm{~cm}$ respectively, with the GIT and LRS accounting for $76.93 \%$ and $19.97 \%$ of the total body weight. The right kidney had a mean length of $0.61 \pm 0.16 \mathrm{~cm}$ while the mean length of the heart was 2.72 $\pm 0.70 \mathrm{~cm}$ and the right ureter was observed to be longer than the left (Table 2).

\section{Anatomical Features}

The esophagus and trachea are hollow organs for conveying food and air into stomach, intestines and lungs respectively. The trachea runs ventral J. Vet. Anat. to the esophagus through the cervical region and bifurcates shortly into the thoracic inlet. The esophagus exits between the points of bifurcation of the bronchi. The syrinx is large and prominent and the lung appearing pink (Fig 1). The proventriculus is dorsally covered by the lobes of the liver and caudally by the gizzard. The intestines form a mass of spiral loops on the right abdominal region, cranially bordered by lobes of the liver, lateral and medial by abdominal wall and gizzard respectively. The gizzard and the intestines are covered by thin and transparent peritoneum (Fig 2).

\section{Discussion}

From this study, the mean body weight was observed to be lower than that of the domestic pigeon and much lower than those of the helmeted guinea fowl lbe, et al. (2008) and Wanmi, (2012). Abumandour (2013) reported that an adult falcon captured in the wild has a weight $150 \mathrm{~g}$ and the weight of different species of birds varies even within the same species. The mean weights of the GTI with its content and GIT without its content were observed to $18.01 \pm 4.80 \mathrm{~g}$ and $13.54 \pm 5.51 \mathrm{~g}$, accounted for 14.94 $\%$ and $11.24 \%$ of the total body weight respectively. The GIT in birds is consist-of the esophagus, crop, stomach and intestines Dyce et al. (2010). In this study it was observed that the wild Senegal parrot does not have cecum as part of the large intestine. It has a colon, rectum and cloa-

Vol. 8, No. 2, (2015) 81 - 88 
$\mathrm{ca}$, the common opening to both GIT and urogenital systems. The mean weight of the liver was higher of all other auxiliary digestive glands, higher than kidneys and tongue. This is in agreement with report on male African grass cutter where the liver was reported to have the highest mean value (Itopa et al. 2012) and its value is higher than other accessory organs of the body. The mean length of the whole body and tail were observed to be $9.85 \pm 1.20 \mathrm{~cm}$ and the GIT to be $82.64 \pm 2.36 \mathrm{~cm}$.

Nasrin et al. (2012) in their findings on the GIT of broilers postnatal, at day 28 , reported a higher value for jejunum to be $123.50 \pm 3.663 \mathrm{~cm}$, far much higher than adult wild Senegal parrot. The lengths of various segment of the intestine depend on the species of bird and their feeding habits Ojo et al. (1987). The mean length of the LRS was observed to be $12.69 \pm 2.10 \mathrm{~cm}$ which was higher than those values reported by Juliana et al. (2005) in partridge Rhenchotus rufescens. Hena et al. (2012) reported higher mean length values of $13.07 \pm 0.72 \mathrm{~cm}$ and $16.47 \pm 1.02 \mathrm{~cm}$ in the lower respiratory tract of the Japanese quail and pigeon respectively. There is slight variation in the length of both ureters in the wild Senegal parrot. This agrees with the finding on the Wister where slight variations were described by Oyeanusi et al. (2009)
Grossly, the esophagus runs down on the midventral aspect of the cervical region through the thorax into the abdominal region. The digestive system lies on the right abdominal region with the gizzard on the left abdominal region. This agrees with the finding of Baumel et al. (1993) who reported that the stomach of chicken lie on the left mid line of the abdomen In the wild Senegal parrot, the cecum is absent and it has been reported by other researchers in other birds (Naik, 1962).

\section{Conclusion}

This study was based on providing some basic morphologic data on the wild Senegal parrot, which its documentation is scanty in this part of the country. The large syrinx and absence of the cecum may suggest that the bird may not be a strict grainivores.

\section{References}

Abumandour, M.M. (2013): Morphological Studies of the Stomach of Falcon. Scientific Journal of Veterinary Advances, ISSN 2322-1879 2(3) 3040

Athan, M and Deter, D. (2000): The African Grey Parrot Handbook. Hauppauge New York: Barron's Educational series. Accessed March 20, 2008 at http://books.google.com/ books?id=qarxmrS2bXQC. 
Baumel, J.J., Anthony, S., King, J.E., Breazile, H.E.E and James, C.V.B. (1993): Handbook of avian anatomy: Nomina Anatomica Avium. $2^{\text {nd }}$ ed. Cambridge: Nuttall Ornithological Club, 779p.

Dyce, K. M and Sack, W.O. (2010): Textbook of Veterinary Anatomy. Fourth Edition, W.B. Saunders Company, Philadelphia, London and Toronto.

Hena, S.A., Sonfadaa, M.L., Belloa, A., Danmaigoroa, $A$ and Tanimomob, B.K. (2012): Comparative Morphologic and Morphometric Studies on the Lower Respiratory Tract of Adult Japanese Quail (coturnix japonica) and Pigeon (columbia livia). Scientific Journal of Biological Sciences 1(2) $37-42$

Ibe, C.S., Onyeanusi, B.I., Salami, S.O., Umosen, A.D and Maidawa, S.M. (2008): Studies of the Major Respiratory Pathways of the West African Guinea Fowl (Numida meleagris galeata): the Morphometric and Macroscopic Aspect, International Journal of Poultry Science 7 (10): 997-1000,ISSN 1682-8356.

Itopa E. A., James, C. S and Wesley, D.N (2012): Organ Body Weight Relationship of Some Organs in the Male African Grasscutter (Thryonomys swinderianus). Journal of Advanced Veterinary Research, Volume 2: $86-90$
Juliana, R.R., Silvana, M. B.A., Daniela, O., Claudinei, da C., Vanessa, S. F and Alex, S. (2005): Morphology of beak and tongue of partridge Rhynchotus rufescens, Ciência Rural, Santa Maria, v35, n.5, p.1098-1102, set-out, ISSN 0103-8478

Naik, D.R. (1962): A study of the intestinal ceca of some Indian birds. M.Sc. Thesis, Banaras Hindu University, Varanasi, India.

Ojo, S.A., Adogwa, A.O and Hambolu, J.O. (1987): The Digestive system, In: Essentials of Veterinary Gross Anatomy, Aahmadu Bello University Press, Zaria. pp. 138-183.

Onyeanusi1, B.I., Adeniyi, O.O., Ayo, J.O., Ibe, S.C and Onyeanusi, C.G. (2009): A Comparative Study on the Urinary System of the African Giant Rat (Cricetomys Gambianus Waterhouse) and the Wistar Rat Pakistan Journal of Nutrition 8 (7): 10431047,ISSN 1680-5194

Wanmi, N. (2012): Anatomical studies of the forebrain and cerebellum of the domestic pigeon (Columba livia domestica). M.Sc. Thesis. Ahmadu Bello University, Zaria.

Wright, M. (2002): "Understanding the Wild Nature of our Dreys" (Online). Accessed April 10, 2008 at http://www.lafeber.com/LaferberLibrary/Articles/wright/wildnature.asp. 


\section{Corresponding Author:}

Wanmi, N; Department of Veterinary Anatomy, College of Veterinary Medicine,

University of Agriculture, Makurdi, Benue State, Nigeria.

e-mail: nathanielwanmi2014@gmail.com

Table (1): Morphometric features of the digestive system of the wild Senegal parrot. $(n=3)$

\begin{tabular}{|l|c|c|c|c|}
\hline \multicolumn{1}{|c|}{ Weight; $(\mathrm{g})$} & Min. Value & Max. Value & Mean \pm SEM & \% Body Weight \\
\hline Weight of whole body & 110.89 & 129.65 & $120.50 \pm 5.42$ & -- \\
\hline Weight of GIT + Content & 11.60 & 27.41 & $18.01 \pm 4.80$ & 14.94 \\
\hline Weight of GIT empty & 5.51 & 24.08 & $13.54 \pm 5.51$ & 11.24 \\
\hline Weight of liver & 1.38 & 7.60 & $4.18 \pm 1.82$ & 3.47 \\
\hline Weight of tongue & 0.48 & 1.93 & $2.76 \pm 2.14$ & 2.29 \\
\hline Weight of the LRS & 3.68 & 8.69 & $5.83 \pm 1.65$ & 4.94 \\
\hline Weight of heart & 1.01 & 3.10 & $1.81 \pm 0.65$ & 1.50 \\
\hline Weight of kidneys & 0.18 & 0.68 & $0.41 \pm 0.05$ & 0.34 \\
\hline
\end{tabular}

g: gram, Mean \pm SEM; Standard Error of Mean

Table (2): Morphometric features of the digestive system of the wild Senegal parrot. $(n=3)$

\begin{tabular}{|l|c|c|c|c|}
\hline \multicolumn{1}{|c|}{ Length $(\mathrm{cm})$} & Min. Value & Max. Value & Mean \pm SEM & \% Body Weight \\
\hline Length of whole body & 12.53 & 17.02 & $9.85 \pm 1.20$ & -- \\
\hline Length of GIT & 76.13 & 95.01 & $82.62 \pm 2.36$ & 76.93 \\
\hline Length of liver & 1.93 & 7.91 & $4.33 \pm 1.82$ & -- \\
\hline Length of tongue & 0.81 & 4.02 & $2.04 \pm 0.99$ & 3.27 \\
\hline Length of LRS & 8.86 & 17.13 & $12.69 \pm 2.10$ & 19.97 \\
\hline Length of the heart & 1.86 & 4.11 & $2.72 \pm 0.70$ & 4.28 \\
\hline Length of left kidney & 0.36 & 0.90 & $0.60 \pm 0.16$ & -- \\
\hline Length of right kidney & 0.37 & 0.91 & $0.61 \pm 0.16$ & -- \\
\hline Length of left ureter & 1.91 & 5.81 & $3.79 \pm 1.13$ & -- \\
\hline Length of right ureter & 1.97 & 6.01 & $3.89 \pm 1.17$ & -- \\
\hline
\end{tabular}

$\mathrm{cm}$; centimeter, Mean \pm SEM; Standard Error of Mean 


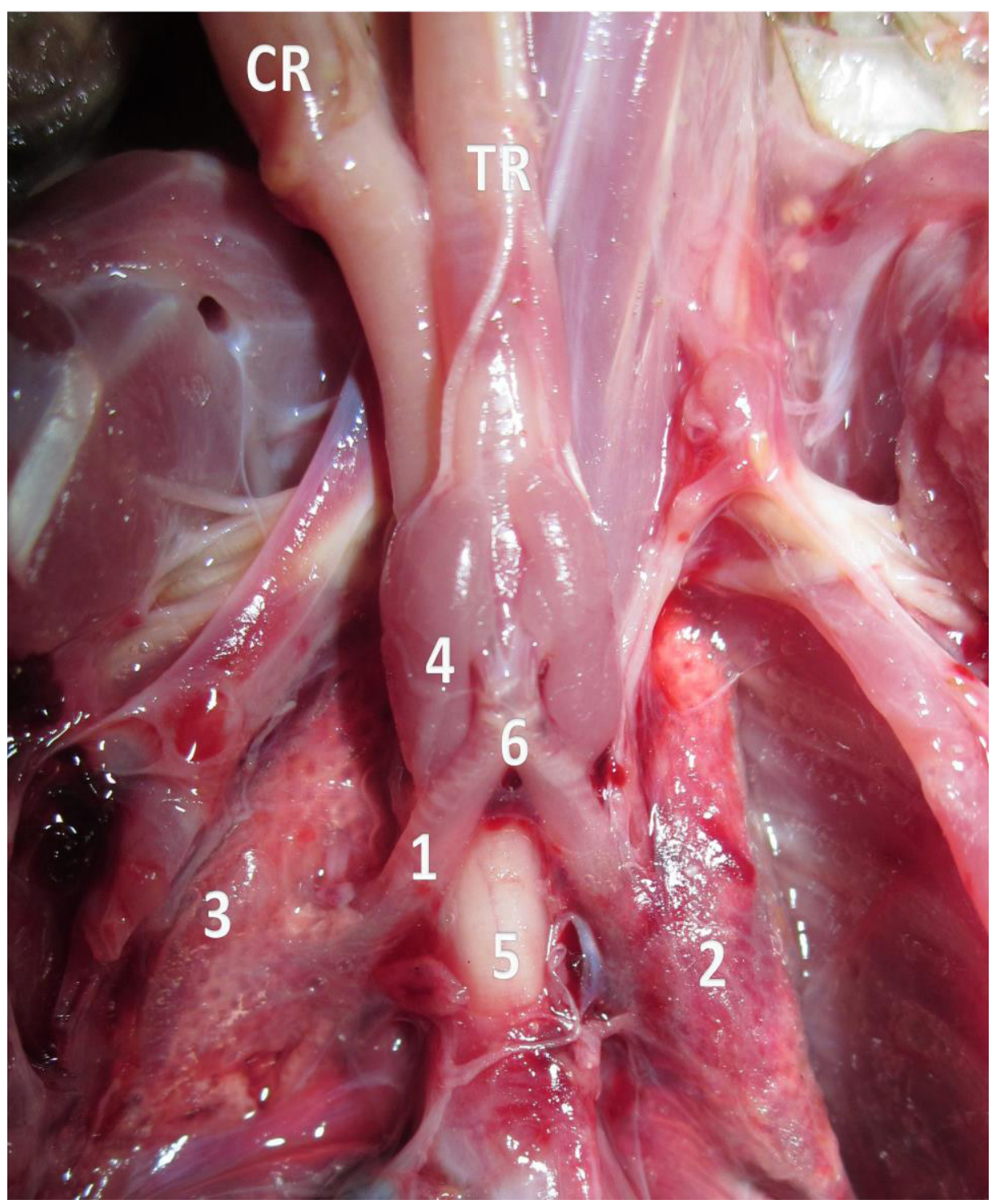

Fig (1): Ventral view of the respiratory system of the African Senegal parrot, showing: TR; Trachea, 1 Bronchus, 2 Left lung, 3 Right lung, 4 Syrinx, 6 Carina. CR Crop, 5 Esophagus 
Body Organs of the Wild African Senegal Parrot

Wanmi er al.,

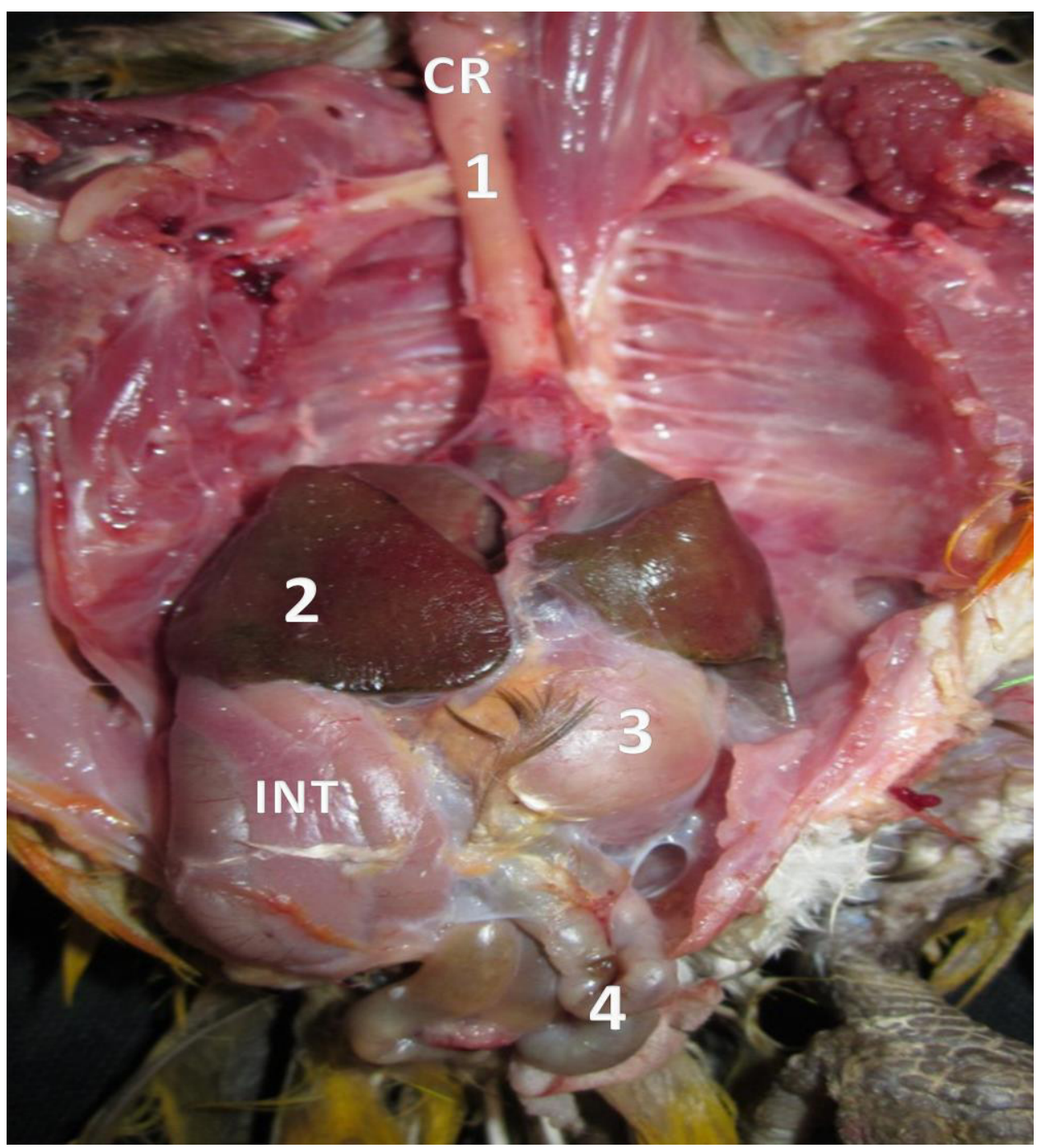

Fig (2): Ventral view of the digestive system of the African Senegal parrot, showing: CR Crop, INT Intestines, 1 Esophagus, 2 Liver, 3 Gizzard, 4 Small Intestine. 